\title{
The Usage of "Quizizz"TM App by Sport Sciences Students in the Bachelor's Degree Anatomy Lecture and Its Effects on Attitude and Course Success
}

\author{
Hikmet Gümüş ${ }^{1}$ \& Celal Gençoğlu \\ ${ }^{1}$ Department of Coaching Education, Faculty of Sport Sciences, Dokuz Eylül University, İzmir, Turkey \\ ${ }^{2}$ Department of Physical Education and Sports Teaching, Faculty of Sport Sciences, Dokuz Eylül University, \\ İzmir, Turkey \\ Correspondence: Celal Gençoğlu, Dokuz Eylül University, Faculty of Sport Sciences, 91/3 No:2, Seferihisar, \\ İzmir, Turkey. E-mail: celal.gencoglu@deu.edu.tr
}

Received: June 14, $2020 \quad$ Accepted: July 21, $2020 \quad$ Online Published: October 25, 2020

doi:10.5539/ies.v13n11p66 URL: https://doi.org/10.5539/ies.v13n11p66

\begin{abstract}
Purpose: The aim of this study is to examine the effects of technologically assisted learning for anatomy courses in sport science collegiate. Methods: One hundred forty-four first-year students from sport sciences faculty attended a required anatomy course in the syllabus. The participants of this class were composed of two learning groups as Classical Learning Group ( $\mathrm{n}=48)$, and New Approach Group $(\mathrm{n}=96)$ based on the lecture style. Classical anatomy course carried out with instruction-based method via PowerPoint lecture on the anatomy course materials such as textbooks, models, and printed visualizations of anatomical sites whereas "Quizizz"TM app-based one performed interactively within a technology-assisted way. The end of the semester, participants answered a reliable and valid survey named Anatomy Lectures Attitude Questionnaire (ALAQ). Results: There was a significant difference in the mid-term and course success when compared Classical Learning (CL) and New Approach (NA). However, no significant differences observed final examination, ALAQ results, and sub-factors'. There was a very low correlation between mid-term, final, course success and ALAQ results in NA group. However, no significantly correlation found between mid-term, final, course success and ALAQ results in CL group. Conclusion: The findings reported here suggest that "Quizizz"TM app can enable improving learning outcomes and contribute to test scores for human anatomy in sport sciences collegiate. We do not conceive the substitute traditional learning method within the educational applications for anatomy courses, but it could be regarded as a supplement method of teaching in higher education.
\end{abstract}

Keywords: human anatomy, gamification, self-exploration, distance learning

\section{Introduction}

Human anatomy is a fundamental lecture in sport science bachelor's degrees and plays a key role in understanding movement patterns. One of the greatest challenges of human anatomy lectures is teaching in the Latin language. Because of intensive content exposure of names and structures of skeletal muscle and bone to be demanded to additional study out of class human anatomy learning outcomes being perceived as high-level difficulty in the sport sciences students. In contrast to the faculty of medicine and health-related institution that usually access to the cadaver, traditional human anatomy lectures carryout with only textbooks, printed 2D figures. However, within increases in mobile devices such as smartphones and tablets recent studies showed raising of usage that devices and applications in the learning process by the collegiate students (Chen, Seilhamer, Bennett, \& Bauer, 2015; Vafa \& Chico, 2013). Technologically assisted anatomy course in the undergraduate level health students revealed that increase learning experiments and caused a better understanding of the course contents (Lynn, Yenser, \& Harman, 2015). In another study showed that computer-assisted learning (CAL) decreased instructor-depended on learning and enabled to achieving learning outcomes. Also, it has been reported that students preferred to CAL or tablets than traditional printed laboratory manuals (Mayfield, Ohara, \& O'Sullivan, 2013). Furthermore, 3D anatomy learning via virtual reality (VR) led to the commitment to the course, higher motivation and has more fun (Moro, Štromberga, \& Stirling, 2017). "Quizizz"TM app one of the most useful applications in education that engage the course material with the gamification concept and self-exploration (Zhao, 2019). This educational application 
enables multi-player activities which are students to have fun while they take part in interactively. Furthermore, users of this app can answer the questions simultaneously in-class and out-class that creates a live scoreboard and ranks the student's instant successes. This gamification way of learning raises the student's engagement and facilitate reaching the learning outcome. Previous studies have established that using "Quizizz"TM app teaching Arabic language (Ju \& Adam, 2018), and physic course (Aşıksoy \& Sorakin, 2018) that effective to enhance students' learning and resulted in better learning outcomes. Findings from several studies suggest that using one of computer-assisted, iPad/Android tablet applications or augmented reality methods could facilitate the teaching, increase the understanding of matter and contribute to the motivational status of students for this course. However, far too little attention has been paid to "Quizizz"TM app-specific investigation of anatomy learning in the sport sciences students. Therefore, the aim of this study is to examine the effects of technologically assisted learning for anatomy courses in sport science collegiate.

\section{Method}

In this study, we investigated retrospectively the human anatomy course during the 2018-2019 and 2019-2020 spring semesters by the same lecturer with two different methods. One hundred forty-four first-year students from sport sciences faculty attended a required anatomy course in the syllabus. The students from two different programs and timelines (Physical Education and Sport Teacher "PETE" and Coaching Education and daytime education and evening education) included in this study, whereas repeating the course was excluded. The participants of this class were composed of 35 female and 109 male students and two learning groups as Classical Learning Group ( $\mathrm{n}=48)$, and New Approach Group $(\mathrm{n}=96)$ based on the lecture style in the attended anatomy course (Table 1).

Table 1. Distributions of students into the education methods, timeline and programs

\begin{tabular}{llcc}
\hline & & Classical Education $(\mathrm{n}=48)$ & New Approach $(\mathrm{n}=96)$ \\
\hline \multirow{2}{*}{ Daytime Education $(\mathrm{n}=110)$} & PETE $(\mathrm{n}=56)$ & 19 & 37 \\
& Coaching Education $(\mathrm{n}=54)$ & 17 & 37 \\
Evening Education $(\mathrm{n}=34)$ & Coaching Education $(\mathrm{n}=34)$ & 12 & 22 \\
\hline
\end{tabular}

Both teaching methods executed to three-hour a week during 14-week that equals to three-ECTS (European Credit Transfer System). Classical anatomy course carried out with instruction-based method via PowerPoint lecture on the anatomy course materials such as textbooks, models, and printed visualizations of anatomical sites whereas "Quizizz"TM app-based one performed interactively within a technology-assisted way. We selected this application as an interactive educational tool for this study that enables gamification in anatomy class (Figure 1). Wireless internet connection provided to the students in the class and asked to download the free application to their mobile phones. After the registration phase, Google classroom created for the course materials and shared with students. Besides the routine of in-class education, "Quizizz"TM app has variations of e-learning tutorials that enable self-explored learning. Also, immediately after the daily class, students could access a small chapter quiz that gives an opportunity to compete (Figure 2). When the class achieved the correct answer rate of $60 \%$ in the quiz, they got the opportunity to access chapter-specialized questions as flashcards for offline. 


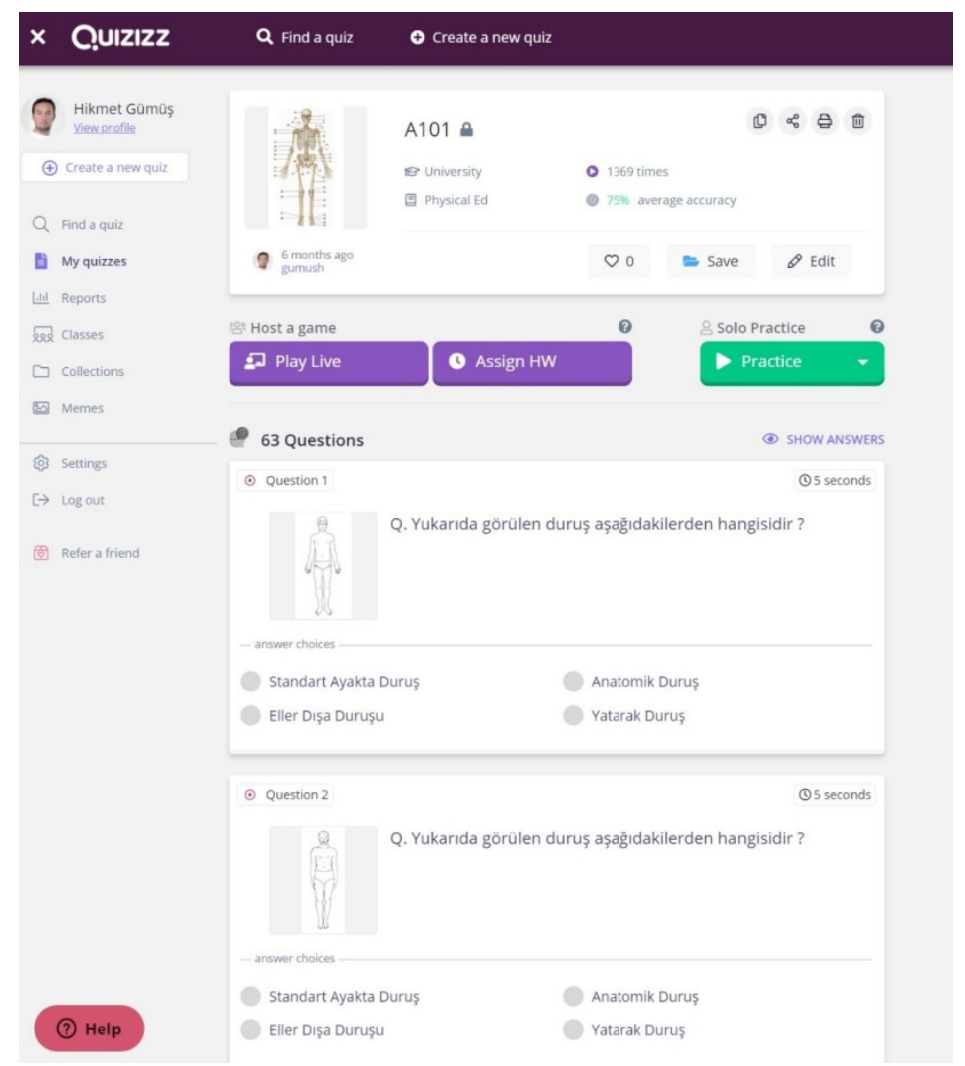

Figure 1. Screenshot of the anatomy course content from the interface of the "Quizizz"TM app

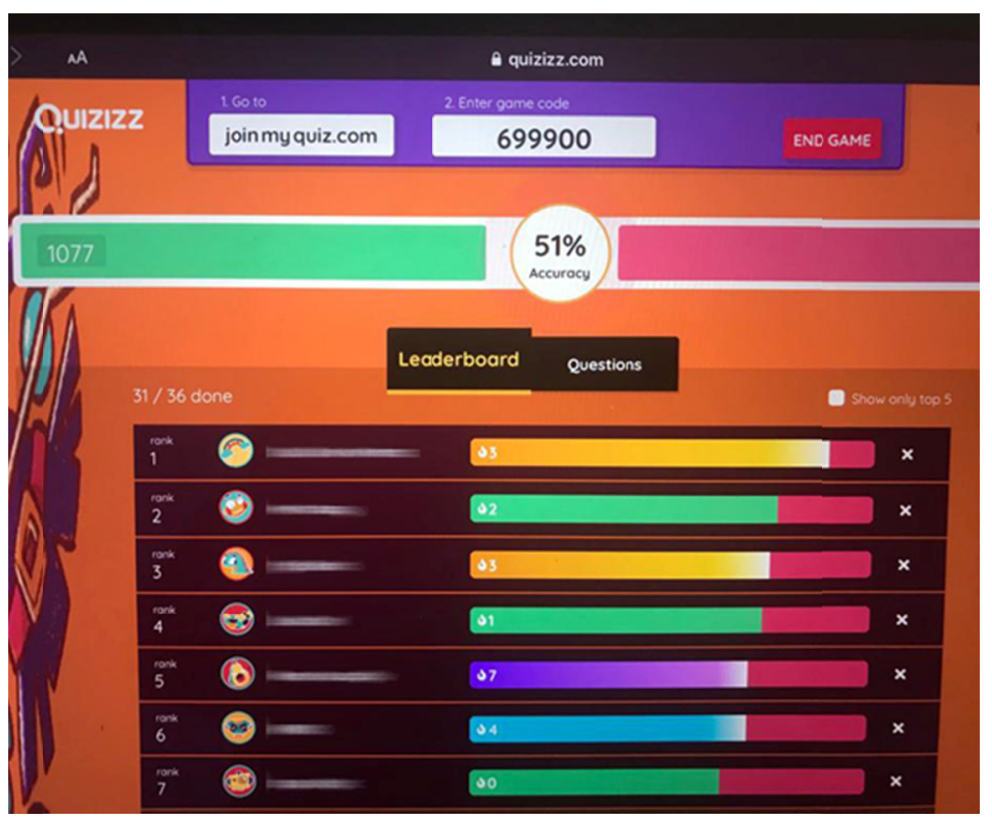

Figure 2. The interface of the "Quizizz"TM apps' screenshot of the gamification-based anatomy learning

After the semester, participants answered a reliable and valid survey named Anatomy Lectures Attitude Questionnaire (ALAQ) which designed in a 5-scale Likert type that contains 24-item (Bahçeci, 2006). The questionnaire creates a score for four sub-factor and total grade depended on varies scores of $0.68-0.79$ Cronbach's Alpha. Anatomy lesson attitude, positive and negative behaviors in the anatomy lesson, anatomy lesson related prejudgments, and belief of anatomy lesson necessity were considered as sub-factors of the survey. 
The total grade of ALAQ varies between 24-120 points and attitude levels divided into three-level such as 24-55 points low-level attitude, 56-88 points medium level attitude, and 89-120 points high-level attitude (Bahçeci, 2006). The ALAQ questionnaire built-in Google forms and delivered to the students to fill this form online. In both groups, the success of the course assessed by $40 \%$ of mid-term and $60 \%$ of the final exam. The mid-term and final exam results obtained from personal transcripts with the permission of faculty. Anatomy lesson final examination time, method and context of the questions were the same for both learning groups. Statistical analysis was performed using SPSS 25 software (IBM Corp. Released 2017. IBM SPSS Statistics for Windows, Version 25.0. Armonk, NY). The Shapiro-Wilk test was used to test the normality of data. We compared the success of course and ALAQ results with a t-test in both groups. The significance level was set up as $\mathrm{p}<0.05$.

\section{Results}

Table 2 presents the comparison of classical learning and new approach methods of the anatomy course as mean, standard deviation, standard error mean, and $\mathrm{p}$ level. There was a significant difference in the mid-term and course success when compared Classical Learning (CL) and New Approach (NA), respectively $\mathrm{p}=0.001$ and $\mathrm{p}=0.008$. However, no significant differences observed in final examination, ALAQ results, and sub-factors'.

Table 2. Anatomy Lesson Attitude Questionnaire and anatomy course success results of different teaching methods

\begin{tabular}{ccccccc}
\hline & Education & N & Mean & Std. Deviation & Std. Error Mean & P value Sig. (2-tailed) \\
\hline \multirow{2}{*}{ Course Success } & Classical Learning & 48 & 73.39 & 14.78 & 2.13 & $.008^{*}$ \\
& New Approach & 96 & 79.60 & 12.27 & 1.25 & $.014^{*}$ \\
\multirow{3}{*}{ Mid-term } & Classical Learning & 48 & 76.27 & 15.03 & 2.16 & $.000^{*}$ \\
& New Approach & 96 & 97.55 & 3.47 & .35 & $.000^{*}$ \\
& Classical Learning & 48 & 69.75 & 19.68 & 2.84 & .541 \\
Final & New Approach & 96 & 67.60 & 19.88 & 2.02 & .540 \\
ALAQ_Total & Classical Learning & 48 & 90.95 & 9.22 & 1.33 & .603 \\
& New Approach & 96 & 91.81 & 9.30 & .95 & .603 \\
ALAQ_Attitude & Classical Learning & 48 & 44.25 & 6.30 & .91 & .985 \\
& New Approach & 96 & 44.27 & 6.40 & .65 & .985 \\
ALAQ_Positive\&Negative & Classical Learning & 48 & 15.04 & 2.82 & .40 & .419 \\
& New Approach & 96 & 15.42 & 2.61 & .26 & .432 \\
ALAQ_Prejudgments & Classical Learning & 48 & 17.56 & 1.91 & .27 & .456 \\
& New Approach & 95 & 17.82 & 1.97 & .20 & .452 \\
ALAQ_Necessity & Classical Learning & 48 & 10.02 & 2.34 & .33 & .611 \\
& New Approach & 95 & 10.25 & 2.67 & .27 & .596 \\
\hline
\end{tabular}

*Significance level is $\mathrm{p}<0.05$.

In the NA group, no significant difference was found between daytime and evening time education for the ALAQ results. Also, with higher examination results t-tests found no significant differences in mean scores on the mid-term, final and course success in the NA group daytime and evening time education. The new approach to anatomy learning showed a significant difference in the mid-term and ALAQ_Prejudgments results between PETE and coaching education (respectively $\mathrm{p}=0.003$ and $\mathrm{p}=0.036$ ). There were very low correlations between mid-term, final, course success and ALAQ results in the NA group (Table 3). Table 4, however, no significant correlation found between mid-term, final, course success and ALAQ results in the CL group. In both groups, a positive correlation between ALAQ_Total and other subfactors were confirmed except the ALAQ_Necessity (Table 3 and Table 4). 
Table 3. Correlations between all parameters in the New Approach Group

\begin{tabular}{|c|c|c|c|c|c|c|c|c|c|}
\hline & & Course Success & Mid-term & Final & ALAQ_Total & ALAQ_A & ALAQ_PN & ALAQ_PJ & ALAQ_N \\
\hline \multirow{2}{*}{ Mid-term } & $\mathrm{r}$ & $.307^{* *}$ & 1 & & & & & & \\
\hline & $\mathrm{p}$ & .002 & & & & & & & \\
\hline \multirow{2}{*}{ Final } & $\mathrm{r}$ & $.994^{* *}$ & $.203^{*}$ & 1 & & & & & \\
\hline & $\mathrm{p}$ & .000 & .047 & & & & & & \\
\hline \multirow{2}{*}{ ALAQ_Total } & $\mathrm{r}$ & $.249^{*}$ & $.324^{* *}$ & $.221^{*}$ & 1 & & & & \\
\hline & $\mathrm{p}$ & .014 & .001 & .031 & & & & & \\
\hline \multirow{2}{*}{ ALAQ_A } & $\mathrm{r}$ & $.268^{* *}$ & $.375^{* *}$ & $.233^{*}$ & $.872^{* *}$ & 1 & & & \\
\hline & $\mathrm{p}$ & .008 & .000 & .022 & .000 & & & & \\
\hline \multirow{2}{*}{ ALAQ_PN } & $\mathrm{r}$ & .192 & .185 & .180 & $.689^{* *}$ & $.427^{* *}$ & 1 & & \\
\hline & $\mathrm{p}$ & .061 & .071 & .080 & .000 & .000 & & & \\
\hline \multirow{2}{*}{ ALAQ_PJ } & $\mathrm{r}$ & .105 & .087 & .097 & $.487^{* *}$ & $.223^{*}$ & $.367^{* *}$ & 1 & \\
\hline & $\mathrm{p}$ & .311 & .404 & .352 & .000 & .030 & .000 & & \\
\hline \multirow{2}{*}{ ALAQ_N } & $\mathrm{r}$ & -.013 & -.039 & -.009 & .191 & -.119 & .043 & -.016 & 1 \\
\hline & $\mathrm{p}$ & .902 & .710 & .935 & .064 & .252 & .677 & .881 & \\
\hline
\end{tabular}

*Correlation is significant at the 0.05 level (2-tailed). ${ }^{* *}$ Correlation is significant at the 0.01 level (2-tailed).

Table 4. Correlations between all parameters in the Classical Group

\begin{tabular}{|c|c|c|c|c|c|c|c|c|c|}
\hline & & Course Success & Mid-term & Final & ALAQ_Total & ALAQ_A & ALAQ_PN & ALAQ_PJ & ALAQ_N \\
\hline \multirow{2}{*}{ Mid-term } & $\mathrm{r}$ & $.818^{* *}$ & 1 & & & & & & \\
\hline & $\mathrm{p}$ & .000 & & & & & & & \\
\hline \multirow{2}{*}{ Final } & $\mathrm{r}$ & $.897^{* *}$ & $.677^{* *}$ & 1 & & & & & \\
\hline & $\mathrm{p}$ & .000 & .000 & & & & & & \\
\hline \multirow{2}{*}{ ALAQ_Total } & $\mathrm{r}$ & .200 & .084 & .221 & 1 & & & & \\
\hline & $\mathrm{p}$ & .172 & .569 & .131 & & & & & \\
\hline \multirow{2}{*}{ ALAQ_A } & $\mathrm{r}$ & .230 & .183 & .229 & $.861^{* *}$ & 1 & & & \\
\hline & $\mathrm{p}$ & .116 & .214 & .118 & .000 & & & & \\
\hline \multirow{2}{*}{ ALAQ_PN } & $\mathrm{r}$ & .020 & -.020 & .020 & $.661^{* *}$ & $.346^{*}$ & 1 & & \\
\hline & $\mathrm{p}$ & .893 & .894 & .894 & .000 & .016 & & & \\
\hline \multirow{2}{*}{ ALAQ_PJ } & $\mathrm{r}$ & .109 & -.037 & .079 & $.531^{* *}$ & .249 & $.417^{* *}$ & 1 & \\
\hline & $\mathrm{p}$ & .459 & .802 & .594 & .000 & .088 & .003 & & \\
\hline \multirow{2}{*}{ ALAQ_N } & $\mathrm{r}$ & .045 & -.087 & .171 & .226 & -.076 & .080 & .002 & 1 \\
\hline & $\mathrm{p}$ & .761 & .557 & .244 & .122 & .605 & .589 & .989 & \\
\hline
\end{tabular}

*Correlation is significant at the 0.05 level (2-tailed). ${ }^{* *}$ Correlation is significant at the 0.01 level (2-tailed).

\section{Discussion}

This study set out to investigate the "Quizizz"TM app as an alternative approach of learning in human anatomy courses for bachelor's degree sport sciences students. The findings of the present study showed that students achieve better examination results with a new approach than the classical method. However, the anatomy lesson attitude perceived by the current technology-assisted learning tool did not show any significant difference.

The main finding of the present study that better mid-term and course success gained with a new approach whereas no improvement observed in the final examination. The observed increase in mid-term and course success could be attributed to the advantages of studying chapter-related questions in every lesson with a new approach method. We could explain the reason for unaffected final examination with accumulated course context, increased learning outcomes and more memorized anatomical sites within the course process. These results reflect those of Brown, Bice, Shaw, \& Shaw, (2015) who also investigated that anatomy and physiology performance by applying online quizzes in kinesiology students. They found that the execution of quizzes immediately after the lecture enhances the learning outcomes while performing after the chapter has no positive effects. Hence, examinations are a stress factor for the students that required high concentration in a short-term period. Because of the executing regularly quizzes by new approach it could be desensitized the students against this stress resulting in a better test grade. Besides the contribution to learning outcome Chaiyo and Nokham, (2017) showed that supporting applications enhance the student's motivation, participation and happiness. The relationship with "Quizizz"TM app and test 
scores observed in this study were contradictory with those unable to establish by Meyer, Stomski, Losco, and Armson (2016) and Noll, Von Jan, Raap, and Albrecht (2017). Meyer et al. (2016) showed that using an application for neuroanatomy learning did not affect the students' grades. Similarly, Noll et al. (2017) could not note significant effects on examination scores by using mobile learning tool. Although the current generation seems to capable to use that technology be in question for anatomy lesson, they would be not to prefer to use it.

Another important finding was that weak but significant positive correlation of mid-term, final, and course success with ALAQ-Total, ALAQ_Attitude in the NA group. However, there was no significant relationship in the CL group. According to our findings, in the study that investigated the students' feedback on the "Quizizz"TM app, Zhao (2019) found that positive perception of the application and also thought to motivate to study. Interestingly, no differences were found in the attitude of the anatomy lessons between classical and new approach methods. Human anatomy is a first-semester lesson in the curriculum of the faculty of sport sciences. These similar ALAQ results may partly be explained by the participation of novice first-year students to this technologically supported new approach. It is possible to expect to lecturer-based instructions in the inexperienced collegiate. All other lessons of faculty carry out via lecturer focused classical method which caused to a misimpression for the new approach. It seems to be possible that the anatomy lesson attitude questionnaire results did not reflect that more funny and interactive lessons with gamification.

It is well known that students' attention time is limited with 15-20 minutes and decreases after the first 10 minutes (Briggs, 2014). Currently grow up the technology in educational science enables us to out-class lessons. Hence, Moraros, Islam, Yu, Banow, and Schindelka, (2015) showed that recorded lessons more preferred by students than classical ones. Previous research findings into technologically supported learning have been inconsistent, especially in anatomy lessons which consider a high-level difficulty. Elizondo-Omaña et al. (2004) reported that a supplement of studying anatomy with computer-assisted new approaches would be beneficial for the student. In another study, investigators found that using a web-based 3-D application named "Essential Skeleton 4" enhanced the test scores of students from exercise and sport sciences such as athletic training, physical education, and sport management (Bice, Carey, Brown, Adkins, \& Ball, 2016). Achieved higher test grades maybe explain that student's study on and take an examination with the only limitation of the skeleton system. Moro et al., (2017) demonstrated that anatomy lessons via virtual reality (VR) perceives more attractive and enjoyable in comparison with traditional teaching. Although this method has advantages, it is clear that cannot provide to understand of complete outcomes. Furthermore, some students had discomforts, tired eyes with this equipment whereas someone interested in VR oculus more than lecture content (Moro et al., 2017). Classical anatomy course has limited hours to access laboratories for cadavers however it does not common to instructions applied in this lab environment. Nevertheless, web-based remotely accessible storage of multiple files such as lesson documents, recorded lecture contents, quizzes may facilitate the students' engagements and study throughout intermittently. These explanations consistent with the previous study that demonstrated students use the app in their way or home regarding limited time in the class (Golenhofen et al., 2020). Moreover, it can be permitted to move or zoom the visuals and read or watch the recorded instructions. These applications also aimed to encourage self-learning, chapters' repetition in self-paced intermittently and take quizzes for the improvement or support the learning process. In contrast to the above-mentioned findings however, Khot, Quinlan, Norman, and Wainman (2013) found that computer-based learning may have significant handicaps in anatomy learning when compared to traditional lectures. In the study that investigated the medical students' behaviors to use the accompanying application for an anatomy course named "eMed-App" and associate with the course successes, Golenhofen et al. (2019) showed that most of the students used this tool especially the students yielded higher grades.

A limitation of using this kind of learning tool is that its dependency on the internet connection and some students may have access problems which resulted in hindering studying out of class. In order to accomplish the goals of a lesson or topic, individual learning styles could differ from other students, however applying a non-specific learning approach in this study is another limitation. Further researches required to evaluate the detailed impact of different supplementary learning tools which enables customized learning styles. Nowadays in education using mobile learning tools or applications such as eMed-App, "Quizizz"TM app, and Kahoot etc. These tools provide to class materials remotely accessible, motivates to students try to self-explored learning and also take part in interactively gamification-based classes and quizzes. The findings reported here suggest that "Quizizz"TM app can enable improving learning outcomes and contribute to test scores for human anatomy in sport sciences collegiate. The pandemic of COVID-19 forced to people to work, meet, teach, and learn from a distance via applications. It seems to distance learning will play a key role in future education. The technological assisted new approach is a useful method to support lessons or courses in human anatomy for bachelor's degree sport sciences students. The current findings add to a growing body of literature on integrating varieties of technology usage in educational 
issues. We do not conceive the substitute traditional learning method within the educational applications for anatomy courses, but we could regard it as a supplement method of teaching in higher education.

\section{Acknowledgments}

There are no conflicts of interest in this paper. This study was not supported by any sources of funding. The authors whose names are listed in this paper certify that they have no affiliations with or involvement in any organization or entity with any financial interest or non-financial interest in the subject matter or materials discussed in this manuscript.

\section{References}

Aşıksoy, G., \& Sorakin, Y. (2018). The Effects Of Clicker-Aided Flipped Classroom Model On Learning Achievement, Physics Anxiety And Students' Perceptions. International Online Journal of Education and Teaching, 5(2), 334-346.

Bahçeci, D. (2006). Anatomi dersinde portfolyo kullanmanın öğrencilerin bilişsel ve duyuşsal özellikleri üzerine etkisi (Yayınlanmamış doktora tezi). Gazi Üniversitesi, Eğitim Bilimleri Enstitüsü, Ankara.

Bice, M. R., Carey, J., Brown, G. A., Adkins, M., \& Ball, J. W. (2016). The use of mobile application to enhance learning of the skeletal system in introductory anatomy \& physiology students. International J. Kinesiology in Higher Education, 27(1), 16-22.

Briggs, S. (2014). The Science of Attention: How To Capture And Hold The Attention of Easily Distracted Students. Retrieved from http://www.opencolleges.edu.au/informed/features/30-tricks-for-capturingstudents-attention/

Brown, G. A., Bice, M. R., Shaw, B. S., \& Shaw, I. (2015). Online quizzes promote inconsistent improvements on in-class test performance in introductory anatomy and physiology. Advances in physiology education, 39(2), 63-66. https://doi.org/10.1152/advan.00064.2014

Chaiyo, Y., \& Nokham, R. (2017). The effect of Kahoot, Quizizz and Google Forms on the student's perception in the classrooms response system. In 2017 International Conference on Digital Arts, Media and Technology (ICDAMT) (pp. 178-182). IEEE. https://doi.org/10.1109/ICDAMT.2017.7904957

Chen, B., Seilhamer, R., Bennett, L., \& Bauer, S. (2015). Students' mobile learning practices in higher education: A multi-year study. Educause Review, 7. Retrieved from https://er.educause.edu/articles/2015/6/students -mobile-learning-practices-in-higher-education-a-multiyear-study

Elizondo-Omaña, R. E., Morales-Gómez, J. A., Guzmán, S. L., Hernández, I. L., Ibarra, R. P., \& Vilchez, F. C. (2004). Traditional teaching supported by computer-assisted learning for macroscopic anatomy. The Anatomical Record Part B: The New Anatomist: An Official Publication of the American Association of Anatomists, 278(1), 18-22. https://doi.org/10.1002/ar.b.20019

Golenhofen, N., Heindl, F., Grab-Kroll, C., Messerer, D. A., Böckers, T. M., \& Böckers, A. (2020). The use of a mobile learning tool by medical students in undergraduate anatomy and its effects on assessment outcomes. Anatomical Sciences Education, 13(1), 8-18. https://doi.org/10.1002/ase.1878

Ju, S. Y., \& Adam, Z. (2018). Implementing Quizizz as game based learning in the Arabic classroom. European Journal of Social Science Education and Research, 5(1), 194-198. https://doi.org/10.2478/ejser-2018-0022

Khot, Z., Quinlan, K., Norman, G. R., \& Wainman, B. (2013). The relative effectiveness of computer-based and traditional resources for education in anatomy. Anatomical sciences education, 6(4), 211-215. https://doi.org/10.1002/ase.1355

Lynn, V. A., Yenser, A., \& Harman, R. (2015). Body apps: iPads for undergrad Anatomy and Physiology students. College \& Research Libraries News, 76(3), 149-152. https://doi.org/10.5860/crln.76.3.9281

Mayfield, C. H., Ohara, P. T., \& O'Sullivan, P. S. (2013). Perceptions of a mobile technology on learning strategies in the anatomy laboratory. Anatomical sciences education, 6(2), 81-89. https://doi.org/10.1002/ase.1307

Meyer, A. J., Stomski, N. J., Losco, C. D., \& Armson, A. J. (2016). The influence of anatomy app use on chiropractic students' learning outcomes: a randomised controlled trial. Chiropractic \& Manual Therapies, 24(1), 44. https://doi.org/10.1186/s12998-016-0125-8

Moraros, J., Islam, A., Yu, S., Banow, R., \& Schindelka, B. (2015). Flipping for success: evaluating the effectiveness of a novel teaching approach in a graduate level setting. BMC medical education, 15(1), 27. 
https://doi.org/10.1186/s12909-015-0317-2

Moro, C., Štromberga, Z., \& Stirling, A. (2017). Virtualisation devices for student learning: Comparison between desktop-based (Oculus Rift) and mobile-based (Gear VR) virtual reality in medical and health science education. Australasian Journal of Educational Technology, 33(6). https://doi.org/10.14742/ajet.3840

Noll, C., von Jan, U., Raap, U., \& Albrecht, U. V. (2017). Mobile augmented reality as a feature for self-oriented, blended learning in medicine: randomized controlled trial. JMIR mHealth and uHealth, 5(9), e139. https://doi.org/10.2196/mhealth.7943

Vafa, S., \& Chico, D. E. (2013). A needs assessment for mobile technology use in medical education. International Journal of Medical Education, 4(1), 230-235. https://doi.org/10.5116/ijme.5259.4a88

Zhao, F. (2019). Using Quizizz to Integrate Fun Multiplayer Activity in the Accounting Classroom. International Journal of Higher Education, 8(1), 37-43. https://doi.org/10.5430/ijhe.v8n1p37

\section{Copyrights}

Copyright for this article is retained by the author(s), with first publication rights granted to the journal.

This is an open-access article distributed under the terms and conditions of the Creative Commons Attribution license (http://creativecommons.org/licenses/by/4.0/). 